\title{
Different approaches to quantify years of life lost from COVID-19
}

\author{
Tamás Ferenci ${ }^{1,2} \mathbb{D}$
}

Received: 19 May 2021 / Accepted: 5 June 2021 / Published online: 10 June 2021

(c) The Author(s) 2021

\begin{abstract}
The burden of an epidemic is often characterized by death counts, but this can be misleading as it fails to acknowledge the age of the deceased patients. Years of life lost is therefore widely used as a more relevant metric, however, such calculations in the context of COVID-19 are all biased upwards: patients dying from COVID-19 are typically multimorbid, having far worse life expectation than the general population. These questions are quantitatively investigated using a unique Hungarian dataset that contains individual patient level data on comorbidities for all COVID-19 deaths in the country. To account for the comorbidities of the patients, a parametric survival model using 11 important long-term conditions was used to estimate a more realistic years of life lost. As of 12 May, 2021, Hungary reported a total of 27,837 deaths from COVID-19 in patients above 50 years of age. The usual calculation indicates 10.5 years of life lost for each death, which decreases to 9.2 years per death after adjusting for 11 comorbidities. The expected number of years lost implied by the life table, reflecting the mortality of a developed country just before the pandemic is 11.1 years. The years of life lost due to COVID-19 in Hungary is therefore $12 \%$ or 1.3 years per death lower when accounting for the comorbidities and is below its expected value, but how this should be interpreted is still a matter of debate. Further research is warranted on how to optimally integrate this information into epidemiologic risk assessments during a pandemic.
\end{abstract}

Keywords COVID-19 $\cdot$ Years of life lost $\cdot$ PYLL $\cdot$ Disease burden $\cdot$ Mortality $\cdot$ Multimorbidity

\section{Introduction}

Quantifying the burden of the COVID-19—or any other infectious disease-is not a straightforward undertaking, primarily due to the multifaceted nature of the problem: "burden" can be measured along several dimensions. Death, time spent with suffering (from anything from a mild cough to the need of invasive ventilation), onset of long-lasting sequelae, direct and indirect consequences of work absenteeism, utilization of the limited healthcare capacity can all be considered "burden" in some sense [1-6].

Perhaps the most widely used indicator of burden is the mortality associated with the epidemic [7]. This can be directly measured, it is considered to be very relevant and

Tamás Ferenci

ferenci.tamas@nik.uni-obuda.hu

1 Physiological Controls Research Center, Obuda University, Bécsi út 96/b, 1034 Budapest, Hungary

2 Department of Statistics, Corvinus University of Budapest, Budapest, Hungary often correlated with other-more difficult to measureindicators [8].

Simply calculating the number of deaths due to COVID19 to measure the burden is associated with two inherent problems $[9,10]$. The first is the definition of dying from the disease: how deaths are attributed in a multimorbid patient is not necessarily unambiguously defined, procedures might be different between countries or change over time. In addition to this uncertainty, deaths may be undercounted if patients are not tested for COVID-19 even post mortem. (This is the reason why the application of excess deaths, that is, the number of deaths minus the number of baseline value, i.e., the number of deaths without epidemic, estimated from historical data, is often called for [11]. Excess death calculation however relies on a baseline, a predicted value, which is always an extrapolation based on historical data, and as such, its reliability necessarily gets worse over time as we are further from the data from which it is predicted. In addition to this, excess death calculation cannot discern thepositive or negative-indirect effects from the direct effects of the epidemic.) These problems will not be addressed in the present paper. 
The second problem, that will be investigated in detail is that raw deaths counts ignore the age of the deceased patient: this calculation gives equal weight to the death of a multimorbid, 80-year-old patient, who only had a few years of life expectancy even without the infection, to the death of a healthy 30-year-old patient, who had several decades of life expectancy. Thus, years of life lost (YLL), first used by Haenszel [12] is widely used to more accurately represent the burden of a disease [13-15].

YLL calculations either assume a fixed target age, to which years lost is measured, or-more typically-use a life table to calculate the expected remaining time (i.e., time lost) for each death [16].

For the COVID-19 pandemic, these calculations are however all biased upwards: patients dying from COVID19 cannot be considered to be a random subsample from the general population. They are usually multimorbid, often having several long-term conditions $[17,18]$, which are themselves associated with reduced life expectancy. The correct calculation should take this into account, by subtracting the age at death from a lower expectation, resulting in a lower number of lost years of life. Calculation of the appropriate expectation is however not straightforward, as life table for patients with comorbidities - and especially for their arbitrary combinations-are not usually available, and are not feasible to produce.

A further important but often overlooked problem about YLL is the appropriate interpretation of its numerical value. "Losing a life year" sounds unequivocally negative, thus one is tempted to automatically assume that the ideal value of YLL is zero. This is not the case however. YLL is based on losing the remaining life expectancy, but this is never zero, so it is mathematically impossible to have a YLL of zeroeven a patient dying at 110 years still loses some remaining life (1.46 years for males, 1.35 for females according to the Hungarian life table).

To tackle this problem, Marshall introduced the concept of life table norm for life years lost, which is the number of years lost by an "average" person in a given population. More precisely, YLL is calculated for a hypothetical cohort undergoing exactly the mortality specified by the life table and the resulting number of years lost is divided by the number of deaths $[19,20]$. In this sense, the norm serves as a reference point, to which actual YLLs can be compared, as the norm signifies what loss is to be expected lacking any special mortality-modifying circumstance. Using a pre-pandemic life table, it can be used represent the expected YLL in individuals who die from causes other than the COVID-19 epidemic. How this should be integrated into the calculation (i.e., should it be simply deducted from the YLL, or only a fraction of it should be deducted) is a matter of debate.

The present study aims to quantitatively explore these issues for the COVID-19 pandemic using data from
Hungary. Uniquely, individual patient level data on comorbidities is publicly available in Hungary for every reported death.

\section{Methods}

Hungarian life table was obtained from the Human Mortality Database for 2017 (the latest available) [21]. Years of life lost for a deceased patient was defined as the expected time remaining according to the life table for the patient's age and sex. YLL is then expressed either as "per death" (when total YLL is divided by the total number of deaths throughout the study period) or "per person-year" (when YLL is divided by the total person-year exposure of the whole background population throughout the study period).

Life table norm was calculated from this life table by summing the product of the number of deaths (from a fixed starting cohort with a size of 100,000 ) and expected remaining years for each age group and dividing it with 100,000.

COVID-19 deaths with individual patient level data on comorbidities were downloaded from the official Hungarian governmental COVID-19 website [22]. This gives information on each patient's year-precision age, sex and comorbidities in an unstructured listing. Eleven comorbidities investigated by Hanlon et al. [23] (atrial fibrillation, cancer, chronic obstructive pulmonary disease (COPD), dementia, diabetes, heart failure, hypertension, ischaemic heart disease (IHD), chronic renal failure, chronic liver disease, stroke) were identified using a regular expression based pattern matching. Search strings are given in Table 1.

Case is ignored everywhere except for the regular expression after OR in case of diabetes and IHD, where case is matched. Hungarian diacritical marks were removed by transliteration to the corresponding non-diacritic equivalent in the original database and the search strings were formed accordingly to reduce the impact of typographical errors.

Although it would be possible to decode any other comorbidity in the above fashion, these 11 were selected, as survival information were available for these from the literature. In more detail, survival models based on age and comorbidities were obtained from Hanlon et al. [23] in the form of a parametric model using Gompertz distribution. Covariates were the 11 comorbidities and their interactions with age, and were assumed to govern the location parameter (i.e., rate) of the distribution [24]. Using the estimated parameters from Hanlon et al. and each individual's covariates, the survival curve for the particular patient was estimated, and expected survival time was calculated by integrating over a 0.1-year wide grid. Separate parameter sets were used for males and females. To account for the overall difference in the survival of the Hungarian population and the databased on the population of Wales-from Hanlon et al., an 
Table 1 Regular expressions used for pattern matching comorbidities in the unstructured list of comorbidities

\begin{tabular}{ll}
\hline Comorbidity & Regular expression \\
\hline Atrial fibrillation & fibril \\
Cancer & rakltumorlnomaldaganatlmetas[z]?tlattet \\
COPD & obstru[clk]tiv[[:blank:]]tudolcopd \\
Dementia & demen \\
Diabetes & diabeteslcukorbeteglmellitus OR DMIIDDMIT1DM|T2DM \\
Heart failure & szivelegtelen \\
Hypertension & h[ily]pertonialmagas[[:blank:]l-]?vernyomas \\
IHD & isch[a]?emias[[:blank:]]szivliszk[a]?emias[[:blank:]]szivlanginalinfar[klc]tus OR IHDICADICHDIAMI \\
Chronic renal failure & kronikus[[:blank:]]vese[[:blank:]l-]?elegtelenlchronicus[[:blank:]]vese[[:blank:]l-]?elegtelen \\
Chronic liver disease & kronikus[[:blank:]]majlchronicus[[:blank:]]majlmajzsugorlmajelegtelenlcirr|kronikus[[:blank:]] \\
Stroke & hepalchronicus[[:blank:]]hepalmajmegnalalkoholos[[:blank:]]maj \\
\hline
\end{tabular}

offset correction was used: the ratio of the life expectancy from the intercept only model of Hanlon et al. to the corresponding data from the Hungarian life table was used to multiply the life expectancy estimated from the survival model.

These survival models are only available for ages above 50 years, so the entire present analysis will be restricted to this age group.

Confidence interval for the prevalence estimates was calculated with Clopper-Pearson exact method [25]. Agespecific prevalence estimates were calculated using a splineregression to smoothly model the effect of age without assuming any parametric functional form [26].

Calculations were carried out under the $\mathrm{R}$ statistical program package version 4.0.4 [27], using package flexsurv version 2.0 [24] and mgcv version 1.8-35 [28].

Full source code of the analysis script is available at https://github.com/tamas-ferenci/YLL_COVID19_Hungary.

\section{Results}

As of 12 May, 2021, Hungary reported a total of 28,970 deaths from COVID-19, of which 27,837 occurred in patients above 50 years of age $(13,667$ females and 14,170 males). Figure 1 shows the distribution of the age of deaths according to sex. The size of the background population is $3,828,818$ [29].

Hungarians in this age group lost a total of 293,519 years of life due to COVID-19 using the ordinary life table approach. This means 10.5 years of life lost for each death (10.3 for females, 10.7 for males), and 0.064 years of life lost per person-year.

Prevalence of the 11 investigated comorbidities is shown on Table 2. In brief, the majority of the deceased patients had hypertension, around third of them were

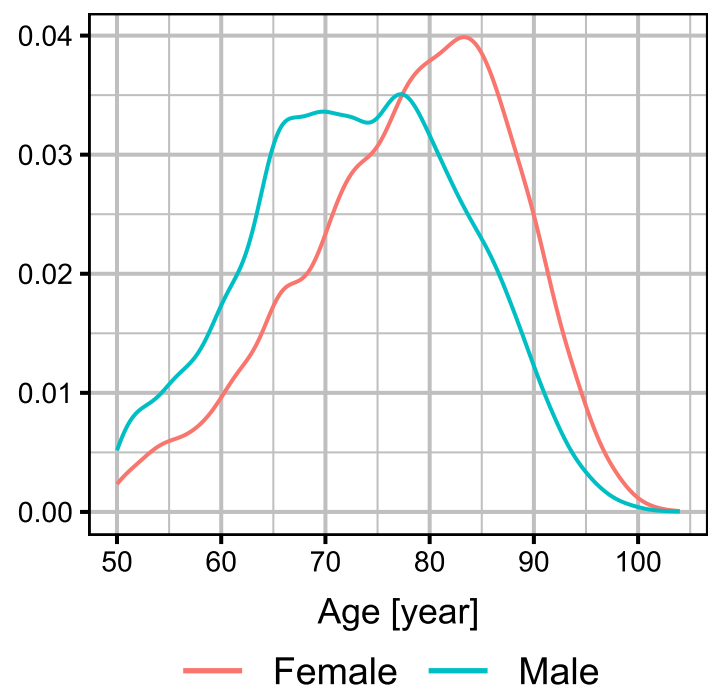

Fig. 1 Distribution of the age of the deceased patients according to sex

diabetic, and more than $10 \%$ had cancer or ischaemic heart disease. The prevalence of the remaining comorbidities was below $10 \%$. Prevalence estimates by age and sex are shown on Fig. 2.

Figure 3 depicts the distribution of the number of comorbidities by age and sex. Overall, $14.1 \%$ of the deceased patients had no comorbidity (from the investigated 11 ones), $36.4 \%$ had a single comorbidity, $33.7 \%$ had two comorbidities and $15.8 \%$ had more than two.

Figure 4 shows the life expectancies of the life table contrasted with the ones provided by the survival model (at individual level, i.e., each dot represents a deceased patient). The difference is immediately obvious: when taking the comorbidities into account, the life expectancy is markedly lower when using the life table, which represents the general population. 
Table 2 Prevalence of the 11 investigated comorbidities (95\% confidence interval in parenthesis)

\begin{tabular}{ll}
\hline Comorbidity & Prevalence [\%] \\
\hline Atrial fibrillation & $3.4(3.2-3.6)$ \\
Cancer & $11.0(10.6-11.3)$ \\
COPD & $3.9(3.6-4.1)$ \\
Dementia & $7.6(7.3-7.9)$ \\
Diabetes & $30.0(29.4-30.5)$ \\
Heart failure & $7.5(7.2-7.8)$ \\
Hypertension & $68.0(67.4-68.5)$ \\
IHD & $14.6(14.2-15.0)$ \\
Chronic liver disease & $0.8(0.7-0.9)$ \\
Chronic renal failure & $5.4(5.1-5.7)$ \\
Stroke & $2.9(2.7-3.1)$ \\
\hline
\end{tabular}

After adjustment for these comorbidities (i.e., using the survival model instead of the life table) the number of years of life lost decreases to 256,043 (9.2 YLL per death-9.0 for females, 9.4 for males - or 0.056 YLL per person-year).

The life table norm of YLL according to the definition of Marshall is 11.1 years (10.3 years for females and 11.9 years for males). This was calculated from the pre-pandemic life table by summing the number of life years lost, the product of life expectancy and the number of deaths for each age group and then dividing it with the number of deaths, i.e., it represents the expected YLL per death due to all causes of death in Hungary, a developed Central European country, but the epidemic.

\section{Discussion}

Burden of any disease can be characterized by its impact on the quality of life, and on life expectancy. The present study focuses on the latter question in the context of the COVID19 epidemic.

As years of life lost better characterize the true burden of the disease than raw death counts, several studies assessed it for the COVID-19 pandemic. Aroles et al. used the international COVerAGE-DB database to calculate YLL for 81 countries, and report a total of 20.5 million years lost as of 6 January, 2021 [30]. They use both reported deaths and excess deaths to account for the potential undercounting. In line with the message of the present paper and that of Hanlon et al., they also note that this number is likely highly biased upwards, thus emphasize the usage of YLL ratios (when YLL is compared to that of other causes, such as influenza, where a similar impact of multimorbidity can be expected). Quast et al. used the ordinary life table approach in the United States and report 1.2 million years of life lost to COVID-19 as of 11 July 2020 [31]. In this study the authors accounted for the effect of multimorbidity by simply reducing the life table remaining years by $25 \%$. Mitra el al evaluated the years of life lost in the United States, Italy and Germany using a fixed target age instead of the life table approach [32]. Rommel et al. reported 305,641 years of life lost in Germany in 2020 using the usual life table method [33]. Goldstein and Lee estimated 11.7 YLL per death, but they make no attempt to account for the comorbidities of the deceased patients [34].

The paper of Hanlon et al. was the first attempt to quantitatively investigate how the accounting for the comorbidities of the patient impacts the estimated years of life lost [23]. However, they had no access to individual patient data on comorbidities and therefore had to rely on an approximate reconstruction of the individual data from aggregate data which is necessarily less efficient and reliable.

Briggs et al. performed a similar analysis, but using an aggregate indicator instead of actual, individual-level data for adjusting for the comorbidities [35].

A unique characteristic of the Hungarian data is that it allows public access to detailed, individual level comorbidities for every registered COVID-19 deaths $(>27,000)$. This allowed a more direct analysis.

Indeed, accounting for 11 comorbidities identified from the Hungarian database decreased the years of life lost by about $12 \%$, which is the first such direct result in the literature to our best knowledge.

The life years lost are however below the norm (as defined by Marshall) even without taking the effect of comorbidities into account. This result might seem counterintuitive at first glance, but is actually entirely possible. Consider the example of Rubo el al [36]: the "public health burden" of a serial killer specifically targeting people above 90 years of age measured in YLL would be almost surely below the norm due to the age of the victims. Simply comparing the YLL to the norm would therefore, at face value, indicate that the activity of a serial killer is beneficial to the public health. This warns us that how the norm should be integrated into the evaluation of the actual YLL of a specific cause is a complicated question.

A few things should be noted about this approach. First, a national life table was used for the ordinary YLL calculations, instead of using a fixed value, or subnational tables [37]. Second, the whole period was used, i.e. no attempt was made to separate different phases of the epidemic. This might be relevant, as different population groups could be affected due to changing non-pharmaceutical interventions, or the introduction of a new variant might alter the agedependent risk for the same group.

The major limitation of the present study is the application of an external survival model to calculate the potential life expectancy for the patients who died. A logical and 


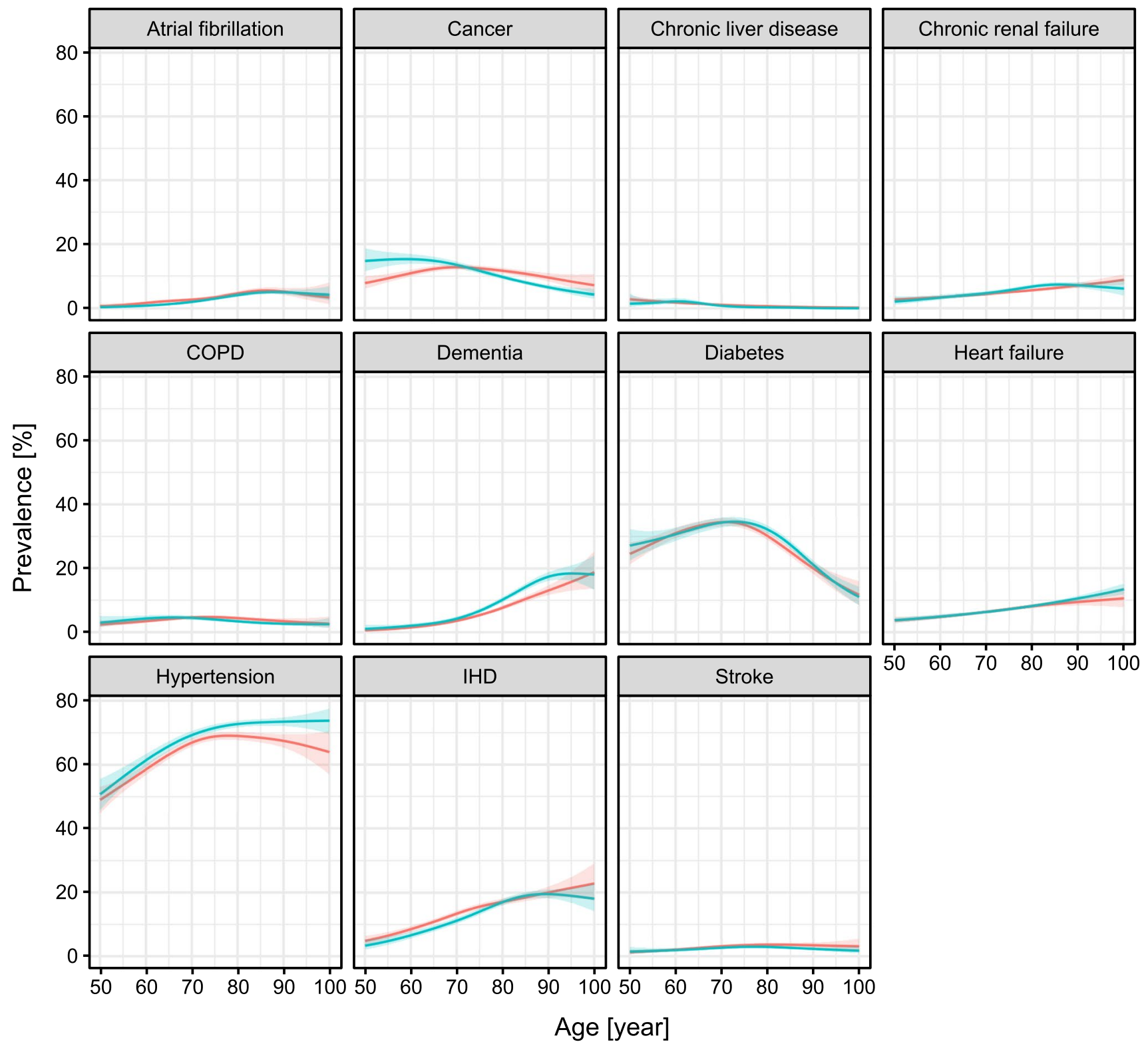

Male — Female

Fig. 2 Prevalence of the investigated 11 comorbidities among the deceased patients according to age and sex with $95 \%$ confidence intervals

important research step would be the calculation and application of a survival model for the comorbidities from the same Hungarian population. Administrative/financial data has been extracted and successfully applied from the Hungarian healthcare system's databases for biomedical research [38-40], so this endeavour seems to be feasible in the future.

Perhaps the most important strength of the present is study is the application of the detailed, individual-level comorbidity database (available for more than 27,000 deaths). However, the data quality is poor, comorbid diseases are entered without any form of standardization, with many typographical errors, arbitrary usage of Latin and Hungarian terminologies, arbitrary usage of abbreviations etc. We tried to overcome these limitations by using carefully selected search expressions to identify the comorbidities, but no formal analysis on the sensitivity or specificity was carried out. We also have no systematic validation on the correctness of the recorded comorbidity data. 

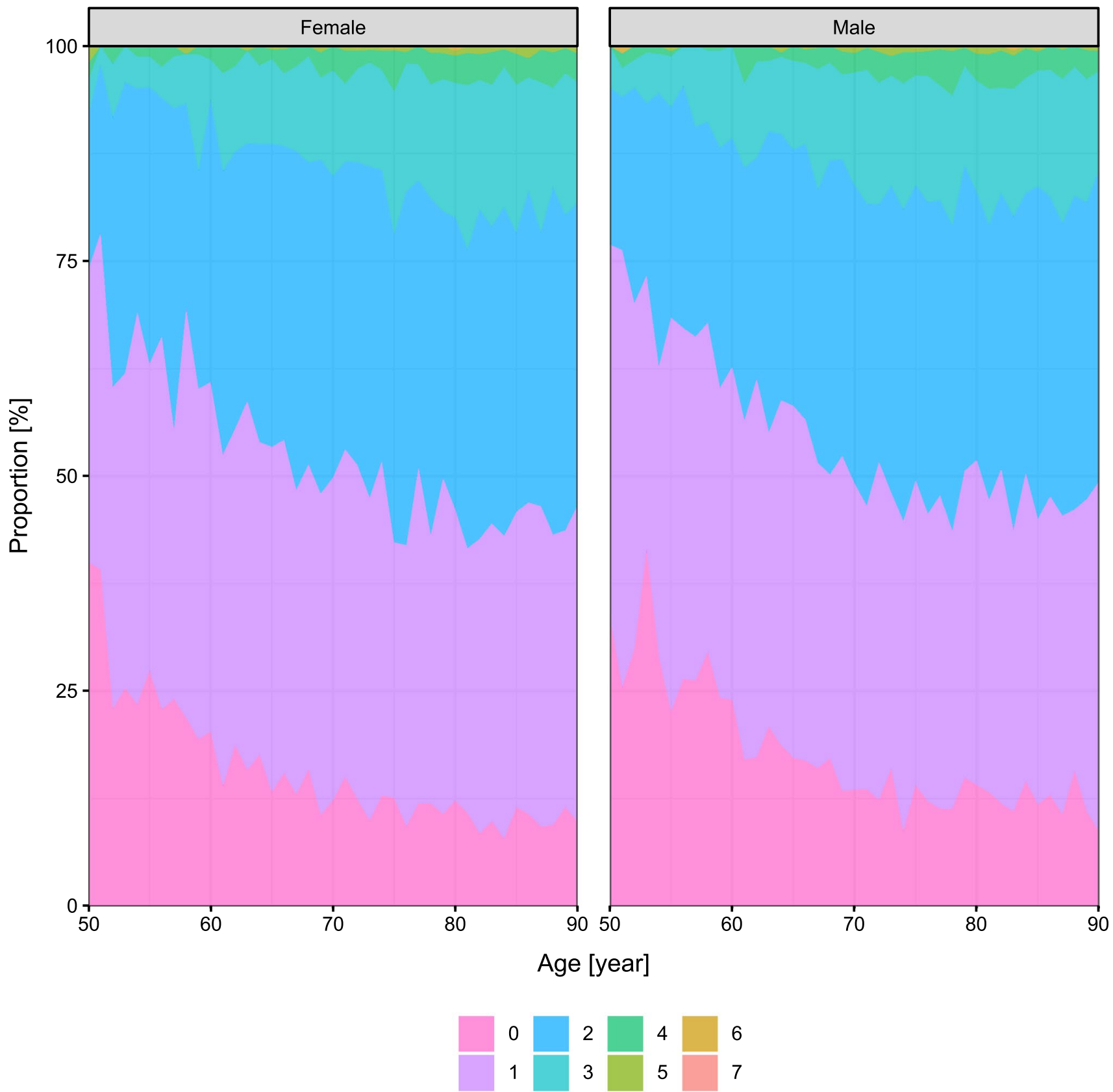

Fig. 3 Distribution of the number of comorbidities of the deceased patients according the age and sex

A third limitation is that only 11 comorbidities were used and no information was available on the severity of the comorbidity.

A final limitation is the application of YLL itself. A recent paper of Rubo et al. argues that the application of YLL is incorrect when there is no clear, causal model of mortality [36]. While strictly speaking we almost never have a perfect such model, this is much less of a problem when the age of death is markedly lower than the age of death in the general population, as this implies that the deaths can be strongly attributed to the investigated factor (as other are unlikely to cause death at early age). Of note, Rubo et al. approvingly refer to the norm-adjustment of Marshall, but take a middle ground between not using it at all, and subtracting the entirety of the norm from the calculated YLL, arguing that this should be decided on how mono-causal is the attribution between the investigated factor and the death. (That is, no subtraction should be made if there is a purely mono-causal relationship, and $100 \%$ of the norm should be deducted if there is no plausible causal mechanism.) What 


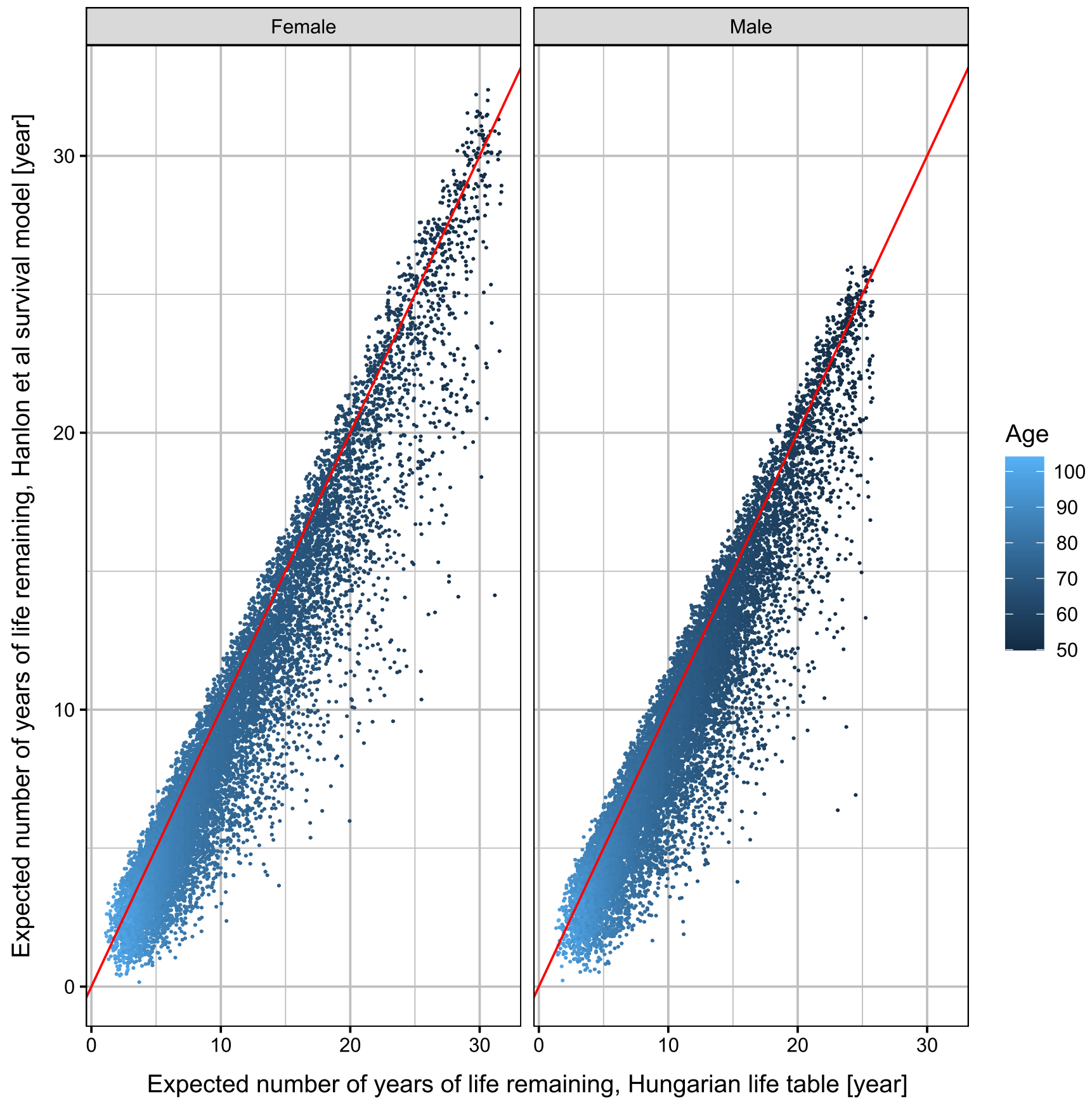

Fig. 4 Jittered scatterplot of life expectancies from the Hungarian life table compared to the ones provided by the survival model, by age and sex; each dot represents a deceased patient

fraction should be deducted in a situation like the COVID19 epidemic, and whether the determination of this fraction is a feasible task at all is perhaps the most intriguing future research direction.

Finally, YLL focuses only on mortality, neglecting the quality of life (QoL) aspect. This is important in two, opposite directions. First, COVID-19 sometimes causes long-lasting sequelae which are detrimental to QoL [41,
42], thus a more complete analysis should also consider this, even if the patient survived the disease. Another, and likely more important consideration is that many of thetypically multimorbid-patients dying from COVID-19 very likely had a reduced QoL even before the infection, so an analysis that adjusts for QoL will reveal an even fewer number of — quality-adjusted-life years lost. 


\section{Conclusion}

Evaluation of the years of life lost is crucial, as it provides a much more relevant insight into the burden of the epidemic than raw death counts. The actual calculation however is not straightforward, and depends on many assumptions which should be carefully assessed. Further research is warranted on how to optimally integrate this information into epidemiologic risk assessments during a pandemic.

Acknowledgements The author would like to express his sincere gratitude to Viktor Müller (Eötvös Loránd University) for his suggestions.

Author contributions TF planned the research, carried out the analysis and prepared the manuscript.

Funding Open access funding provided by Óbuda University. No funding was received for conducting this study.

Data Availability and material https://github.com/tamas-ferenci/YLL_ COVID19_Hungary.

\section{Declarations}

Conflict of interest The author has no conflict of interest to declare that are relevant to the content of this article.

Code availability https://github.com/tamas-ferenci/YLL_COVID19_ Hungary.

Open Access This article is licensed under a Creative Commons Attribution 4.0 International License, which permits use, sharing, adaptation, distribution and reproduction in any medium or format, as long as you give appropriate credit to the original author(s) and the source, provide a link to the Creative Commons licence, and indicate if changes were made. The images or other third party material in this article are included in the article's Creative Commons licence, unless indicated otherwise in a credit line to the material. If material is not included in the article's Creative Commons licence and your intended use is not permitted by statutory regulation or exceeds the permitted use, you will need to obtain permission directly from the copyright holder. To view a copy of this licence, visit http://creativecommons.org/licenses/by/4.0/.

\section{References}

1. Murray CJL, Lopez AD. Measuring the global burden of disease. N Engl J Med. 2013;369:448-57. https://doi.org/10.1056/ NEJMra1201534.

2. Kretzschmar M, Mangen M-JJ, Pinheiro P, et al. New methodology for estimating the burden of infectious diseases in Europe. PLoS Med. 2012. https://doi.org/10.1371/journal.pmed.10012 05.

3. van Lier EA, Havelaar AH, Nanda A. The burden of infectious diseases in Europe: a pilot study. Eurosurveillance. 2007;12:34. https://doi.org/10.2807/esm.12.12.00751-en.

4. Li S, Leader S. Economic burden and absenteeism from influenza-like illness in healthy households with children (5-17 years) in the US. Respir Med. 2007;101:1244-50. https://doi. org/10.1016/j.rmed.2006.10.022.

5. Sachs J, Malaney P. The economic and social burden of malaria. Nature. 2002;415:680-5. https://doi.org/10.1038/415680a.

6. Kwong JC, Ratnasingham S, Campitelli MA, et al. The impact of infection on population health: results of the ontario burden of infectious diseases study. PLoS ONE. 2012;7: e44103. https://doi.org/10.1371/journal.pone.0044103.

7. Armstrong GL. Trends in infectious disease mortality in the United States during the 20th century. JAMA. 1999;281:61. https://doi.org/10.1001/jama.281.1.61.

8. Setel P, AbouZahr C, Atuheire EB, et al. Mortality surveillance during the COVID-19 pandemic. Bull World Health Organ. 2020;98:374-374. https://doi.org/10.2471/BLT.20.263194.

9. Sornette D, Mearns E, Schatz M, et al. Interpreting, analysing and modelling COVID-19 mortality data. Nonlinear Dyn. 2020;101:1751-76. https://doi.org/10.1007/ s11071-020-05966-z.

10. Noordzij M, Vart P, Duivenvoorden R, et al. Pitfalls when comparing COVID-19-related outcomes across studies-lessons learnt from the ERACODA collaboration. Clin Kidney J. 2021;14:i14-20. https://doi.org/10.1093/ckj/sfab027.

11. Leon DA, Shkolnikov VM, Smeeth L, et al. COVID-19: a need for real-time monitoring of weekly excess deaths. The Lancet. 2020;395: e81. https://doi.org/10.1016/S0140-6736(20) 30933-8.

12. Haenszel W. A standardized rate for mortality defined in units of lost years of life. Am J Public Health Nations Health. 1950;40:1726. https://doi.org/10.2105/AJPH.40.1.17.

13. Martinez R, Soliz P, Caixeta R, Ordunez P. Reflection on modern methods: years of life lost due to premature mortality-a versatile and comprehensive measure for monitoring non-communicable disease mortality. Int J Epidemiol. 2019;48:1367-76. https://doi. org/10.1093/ije/dyy254.

14. Stickle G. What priority, human life? Am J Public Health Nations Health. 1965;55:1692-8. https://doi.org/10.2105/AJPH.55.11. 1692.

15. Gardner JW, Sanborn JS (1990) Years of Potential Life Lost (YPLL) —What Does it Measure?: Epidemiology 1: 322-329

16. Bonneux L. How to measure the burden of mortality? J Epidemiol Community Health. 2002;56:128-31. https://doi.org/10.1136/ jech.56.2.128.

17. Piroth L, Cottenet J, Mariet A-S, et al. Comparison of the characteristics, morbidity, and mortality of COVID-19 and seasonal influenza: a nationwide, population-based retrospective cohort study. Lancet Respir Med. 2021;9:251-9. https://doi.org/10.1016/ S2213-2600(20)30527-0.

18. Wortham JM, Lee JT, Althomsons S, et al (2020) Characteristics of Persons Who Died with COVID-19 — United States, February 12-May 18, 2020. MMWR Morb Mortal Wkly Rep 69:923-929 https://doi.org/10.15585/mmwr.mm6928e1

19. Marshall RJ. Standard expected years of life lost as a measure of mortality: norms and reference to New Zealand data. Aust N Z J Public Health. 2004;28:452-7. https://doi.org/10.1111/j.1467842X.2004.tb00027.x.

20. Marshall RJ. Standard expected years of life lost as a measure of disease burden: an investigation of its presentation, meaning and interpretation. In: Preedy VR, Watson RR, editors. Handbook of Disease Burdens and Quality of Life Measures. New York, New York, NY: Springer; 2010. p. 401-13.

21. Human Mortality Database. University of California, Berkeley (USA), and Max Planck Institute for Demographic Research (Germany). Available at www.mortality.org or www.humanmortality. de (data downloaded on 9 March, 2021)

22. Tájékoztató oldal a koronavírusról. URL: https://koronavirus.gov. $\mathrm{hu} /$. 
23. Hanlon P, Chadwick F, Shah A, et al (2021) COVID-19-exploring the implications of long-term condition type and extent of multimorbidity on years of life lost: a modelling study. Wellcome Open Res 5:75. https://doi.org/10.12688/wellcomeopenres. 15849.3

24. Jackson C (2016) flexsurv: A Platform for Parametric Survival Modeling in R. J Stat Softw 70:. https://doi.org/10.18637/jss. v070.i08

25. Clopper CJ, Pearson ES. The use of confidence or fiducial limits illustrated in the case of the binomial. Biometrika. 1934;26:40413. https://doi.org/10.1093/biomet/26.4.404.

26. Wood SN. Thin plate regression splines: thin plate regression splines. J R Stat Soc Ser B Stat Methodol. 2003;65:95-114. https://doi.org/10.1111/1467-9868.00374.

27. R Core Team (2021). R: A language and environment for statistical computing. R Foundation for Statistical Computing, Vienna, Austria. URL https://www.R-project.org/

28. Wood SN. Generalized additive models: an introduction with R. 2nd ed. Boca Raton: CRC Press/Taylor \& Francis Group; 2017.

29. Központi Statisztikai Hivatal (KSH) STADAT 22.1.1.3. Népesség korév és nem szerint, január 1. URL: http://www.ksh.hu/stadat_ files/nep/hu/nep0003.html. Accessed: 14-May-2021.

30. Pifarré i Arolas H, Acosta E, López-Casasnovas G, et al (2021) Years of life lost to COVID-19 in 81 countries. Sci Rep 11:3504 https://doi.org/10.1038/s41598-021-83040-3

31. Quast T, Andel R, Gregory S, Storch EA. Years of life lost associated with COVID-19 deaths in the United States. J Public Health. 2020;42:717-22. https://doi.org/10.1093/pubmed/fdaa159.

32. Mitra AK, Payton M, Kabir N, et al. Potential years of life lost due to COVID-19 in the United States, Italy, and Germany: an old formula with newer ideas. Int J Environ Res Public Health. 2020;17:4392. https://doi.org/10.3390/ijerph17124392.

33. Rommel A, von der Lippe E, Plaß D, et al. The COVID-19 disease burden in Germany in 2020 - years of life lost to death and disease over the course of the pandemic. Dtsch Aerzteblatt Online. 2021. https://doi.org/10.3238/arztebl.m2021.0147.

34. Goldstein JR, Lee RD. Demographic perspectives on the mortality of COVID-19 and other epidemics. Proc Natl Acad Sci. 2020;117:22035-41. https://doi.org/10.1073/pnas.2006392117.
35. Briggs AH, Goldstein DA, Kirwin E, et al. Estimating (qualityadjusted) life-year losses associated with deaths: With application to COVID-19. Health Econ. 2021;30:699-707. https://doi.org/10. 1002/hec.4208.

36. Rubo M, Czuppon P (2020) Years of life lost estimates cannot always be taken at face value: Response to "COVID-19-exploring the implications of long-term condition type and extent of multimorbidity on years of life lost: a modelling study." Wellcome Open Res 5:137. https://doi.org/10.12688/wellcomeopenres. 16015.1

37. Devleesschauwer B, McDonald SA, Speybroeck N, Wyper GMA. Valuing the years of life lost due to COVID-19: the differences and pitfalls. Int J Public Health. 2020;65:719-20. https://doi.org/ 10.1007/s00038-020-01430-2.

38. Kolossváry E, Ferenci T, Kováts T, et al. Trends in major lower limb amputation related to peripheral arterial disease in hungary: a nationwide study (2004-2012). Eur J Vasc Endovasc Surg. 2015;50:78-85. https://doi.org/10.1016/j.ejvs.2015.02.019.

39. Kolossváry E, Ferenci T, Kováts T. Potentials, challenges, and limitations of the analysis of administrative data on vascular limb amputations in health care. Vasa. 2020;49:87-97. https://doi.org/ 10.1024/0301-1526/a000823.

40. Horvath A, Pall N, Molnar K, et al. A nationwide study of the epidemiology of relapsing polychondritis. Clin Epidemiol. 2016;8:211-30. https://doi.org/10.2147/CLEP.S91439.

41. Mahase E (2020) Covid-19: What do we know about "long covid"? BMJ m2815. https://doi.org/10.1136/bmj.m2815

42. Yelin D, Wirtheim E, Vetter $P$, et al. Long-term consequences of COVID-19: research needs. Lancet Infect Dis. 2020;20:1115-7. https://doi.org/10.1016/S1473-3099(20)30701-5.

Publisher's Note Springer Nature remains neutral with regard to jurisdictional claims in published maps and institutional affiliations. 